\title{
Stroke prevention in the elderly atrial fibrillation patient with comorbid conditions: focus on non-vitamin $\mathrm{K}$ antagonist oral anticoagulants
}

This article was published in the following Dove Press journal:

Clinical Interventions in Aging

3 September 2015

Number of times this article has been viewed

\author{
Mohit K Turagam \\ Poonam Velagapudi \\ Greg C Flaker \\ Division of Cardiovascular Medicine, \\ University of Missouri School of \\ Medicine, Columbia, MO, USA
}

\begin{abstract}
Stroke prevention in elderly atrial fibrillation patients remains a challenge. There is a high risk of stroke and systemic thromboembolism but also a high risk of bleeding if anticoagulants are prescribed. The elderly have increased chronic kidney disease, coronary artery disease, polypharmacy, and overall frailty. For all these reasons, anticoagulant use is underutilized in the elderly. In this manuscript, the benefits of non-vitamin $\mathrm{K}$ antagonist oral anticoagulants compared with warfarin in the elderly patient population with multiple comorbid conditions are reviewed.
\end{abstract}

Keywords: non-vitamin $\mathrm{K}$ antagonist oral anticoagulants, novel oral anticoagulants, warfarin, dabigatran, rivaroxaban, apixaban, edoxaban

\section{Introduction}

Atrial fibrillation (AF) is the most common cardiac dysrhythmia seen in clinical practice and is associated with increased risk of morbidity and mortality from stroke and systemic thromboembolism. ${ }^{1,2}$ Oral anticoagulation therapy (OAC) with warfarin or one of the non-vitamin $\mathrm{K}$ antagonist oral anticoagulants (NOACs), including a direct thrombin inhibitor (dabigatran) and factor Xa inhibitors (rivaroxaban, apixaban, and edoxaban) are recommended for AF in patients with risk factors but is underutilized. ${ }^{3}$ One of the reasons for this underutilization is the perceived unfavorable risk-benefit ratio in certain populations. This review will focus on the role of oral anticoagulation including warfarin and NOACs in populations with common comorbid conditions including age, chronic kidney disease (CKD), coronary artery disease (CAD), polypharmacy, and frailty.

\section{NOACs versus warfarin in patients with AF, aged $\geq 75$ years}

Aging is an important risk factor for patients with AF. The estimated prevalence of AF in patients aged $\geq 80$ years is $9 \%-10 \%$ and is $<0.1 \%$ in patients aged $\leq 55$ years. ${ }^{1,4,5}$ AF is associated with a four- to fivefold increased risk of embolic stroke with an estimated increased stroke risk of 1.45-fold per decade in aging. ${ }^{6,7}$ Older age is also associated with an increased risk of major bleeding with OAC therapy. Despite the inherent risk of increased bleeding, OAC therapy lowers the risk of stroke, systemic thromboembolism, and mortality in AF. ${ }^{8}$

Although warfarin has been the mainstay treatment for prevention of stroke and systemic thromboembolism in AF, randomized controlled trials (RCTs) have demonstrated either non-inferiority or superiority in the prevention of stroke and systemic 
thromboembolism. In these trials the risk of major bleeding was comparable to or superior to warfarin..$^{9-12}$ In pre-specified subgroup analyses in the elderly (aged $\geq 75$ years) the four trials have shown, in general, similar findings. Stroke and systemic emboli rates are increased as is major bleeding compared with patients $<75$ years. NOACs do result in a reduction in stroke and systemic emboli and a reduction in major bleeding compared with warfarin but with heterogeneity of results between the trials in terms of major bleeding (Table 1).

The Randomized Evaluation of Long-Term Anticoagulation Therapy (RE-LY) trial included patients with a mean CHADS2 (Congestive heart failure, Hypertension, Age $\geq 75$ years, Diabetes, Stroke or transient ischemic attack) score of 2.2 and a mean age of 71.5 years. RE-LY showed dabigatran $150 \mathrm{mg}$ twice daily was associated with lower rates of stroke and systemic thromboembolism (1.1\%/year vs $1.7 \%$ year, hazard ratio [HR], $0.66 ; 95 \%$ confidence interval [CI] [0.53-0.82]; $P<0.001)$ and comparable rates of major bleeding with warfarin (3.1\%/year vs 3.4\%/year, HR, 0.93; 95\% CI [0.81-1.07]; $P=0.31) .{ }^{9}$ In patients aged $\geq 75$ years, dabigatran $150 \mathrm{mg}$ twice daily resulted in a similar reduction in stroke and systemic thromboembolism compared with warfarin $(1.4 \%$ /year vs $2.1 \%$ /year, HR, $0.67 ; 95 \% \mathrm{CI}$ [0.49-0.9]; $P=0.81$ ). However, when compared with warfarin, dabigatran $150 \mathrm{mg}$ twice daily was associated with a lower risk of major bleeding in patients $<75$ years $(2.1 \%$ year vs 3\%/year, HR, 0.70; 95\% CI [0.57-0.86]; $P<0.001)$ but a trend toward more major bleeding in patients $>75$ years $(5.1 \% /$ year vs $4.3 \%$ /year, HR, 1.18 ; 95\% CI [0.98-1.42]; $P<0.001) .{ }^{13}$
The Rivaroxaban Once Daily Oral Direct Factor Xa Inhibition Compared with Vitamin K Antagonism for Prevention of Stroke and Embolism Trial in Atrial Fibrillation (ROCKET-AF) included patients with a mean CHADS2 score of 3.5 and a median age of 73 years. ROCKET-AF showed rivaroxaban was associated with lower rate of stroke and systemic thromboembolism (1.7\%/year vs $2.2 \%$ /year, HR, $0.79 ; 95 \%$ CI [0.66-0.96]; $P<0.001)$ with similar rates of major bleeding when compared with warfarin $(3.6 \% /$ year vs $3.4 \%$ year, HR 1.03 ; 95\% CI, [0.96-1.11]; $P=0.44) .{ }^{10}$

On-treatment analysis further demonstrated lower rate of stroke and systemic thromboembolism with rivaroxaban vs warfarin ( $1.7 \%$ /year vs $2.2 \%$ /year; $P=0.02)$.

In patients aged $\geq 75$ years, rivaroxaban resulted in a similar reduction in stroke and systemic thromboembolism compared with warfarin $(2.3 \%$ /year vs $2.8 \%$ /year, HR $0.80 ; 95 \%$ CI [0.63-1.02]; $P=0.3$ ). Daily rivaroxaban was associated with a similar risk of major bleeding in patients $<75$ years $(2.7 \%$ /year vs $2.8 \%$ /year, HR 0.96 ; 95\% CI [0.78-1.19]; $P=0.3$ ) but a trend toward more major bleeding in patients $>75$ years $(4.8 \%$ /year vs $4.4 \%$ year, HR 1.1; 95\% CI [0.92-1.34]; $P=0.3) .{ }^{10,14}$

The Reduction in Stroke and Other Thromboembolic Events in Atrial Fibrillation (ARISTOTLE) trial included patients with a mean CHADS2 score of 2.1 and a median age of 70 years. ARISTOTLE showed apixaban was associated with lower rate of stroke and systemic thromboembolism (1.3\%/year vs $1.6 \%$ year, HR $0.79 ; 95 \%$ CI [0.66-0.95]; $P<0.001)$ with lower rates of major bleeding when compared

Table I Summary of risk of stroke/thromboembolism and major bleeding comparing direct oral anticoagulants and warfarin in patients aged $>75$ years and $<75$ years

\begin{tabular}{|c|c|c|c|c|}
\hline & \multicolumn{2}{|c|}{ Stroke/systemic thromboembolism (\%/year) } & \multicolumn{2}{|c|}{ Major bleeding (\%/year) } \\
\hline & Age $<75$ years $*$ & Age $>75$ years & Age $<75$ years* & Age $>75$ years \\
\hline \multicolumn{5}{|l|}{ RE-LY } \\
\hline Dabigatran 150 mg & 0.9 & 1.4 & 2.1 & 5.1 \\
\hline Warfarin & $\mathrm{I} .4$ & 2.1 & 3 & 4.4 \\
\hline \multicolumn{5}{|l|}{ ROCKET-AF } \\
\hline Rivaroxaban & 2 & 2.3 & 2.7 & 4.9 \\
\hline Warfarin & 2.1 & 2.9 & 2.8 & 4.4 \\
\hline \multicolumn{5}{|l|}{ ARISTOTLE } \\
\hline Apixaban & 1.2 & 1.6 & 2 & 3.3 \\
\hline Warfarin & 1.7 & 2.2 & 2.8 & 5.2 \\
\hline \multicolumn{5}{|l|}{ ENGAGE-TIMI 48} \\
\hline Edoxaban - high intensity & 1.7 & 1.9 & 2.5 & 4 \\
\hline Edoxaban - low intensity & 2.6 & 2.6 & 1.6 & 2.3 \\
\hline Warfarin & 1.8 & 2.3 & 3.3 & 4.8 \\
\hline
\end{tabular}

Note: *Age $<75$ years: includes patients between 65 and 74 years.

Abbreviations: RE-LY, Randomized Evaluation of Long-Term Anticoagulation Therapy; ROCKET-AF, Rivaroxaban Once Daily Oral Direct Factor Xa Inhibition Compared with Vitamin K Antagonism for Prevention of Stroke and Embolism Trial in Atrial Fibrillation; ARISTOTLE, Reduction in Stroke and Other Thromboembolic Events in Atrial Fibrillation trial; ENGAGE-TIMI 48, Effective Anticoagulation with Factor Xa Next Generation in Atrial Fibrillation-Thrombolysis in Myocardial Infarction 48 trial. 
with warfarin $(2.1 \%$ year vs $3.1 \%$ year, HR $0.69 ; 95 \%$ CI $[0.60-0.80] ; P<0.001) .{ }^{11}$ In patients aged $\geq 75$ years, apixaban resulted in a similar reduction in stroke and systemic thromboembolism compared with warfarin $(1.6 \%$ year vs $2.2 \%$ /year, HR $0.71 ; 95 \%$ CI [0.53-0.95]; $P=0.11$ ). Apixaban was associated with a lower risk of major bleeding in both patients $<75$ years $(2 \%$ /year vs $2.8 \%$ /year, HR $0.71 ; 95 \%$ CI [0.56-0.89]; $P=0.63)$ and in patients $>75$ years $(3.3 \% /$ year vs 5.2\%/year, HR 0.64; 95\% CI [0.52-0.79]; $P=0.63$ ) when compared with warfarin. ${ }^{11,15,16}$

The Effective Anticoagulation with Factor Xa Next Generation in Atrial Fibrillation-Thrombolysis in Myocardial Infarction (ENGAGE-TIMI) 48 trial included patients with a mean CHADS2 score of 2.8 and a median age of 72 years. ENGAGE-TIMI 48 showed oral edoxaban was associated with lower rate of stroke and systemic thromboembolism (1.2\%/year vs $1.5 \%$ /year, HR, 0.79; 97.5\% CI [0.63-0.99]; $P<0.001)$ with lower rates of major bleeding when compared with warfarin $(2.7 \%$ /year vs $3.4 \%$ /year, HR $0.80 ; 95 \%$ CI [0.71-0.91]; $P<0.001) .{ }^{12}$ In patients aged $\geq 75$ years, both edoxaban $60 \mathrm{mg}$ daily and $30 \mathrm{mg}$ daily resulted in a similar reduction in stroke and systemic thromboembolism compared with warfarin (edoxaban $60 \mathrm{mg} ; 1.9 \%$ /year vs $2.3 \%$ /year, HR $0.83 ; P=$ non-significant) and edoxaban $30 \mathrm{mg} ; 2.6 \% /$ year vs $2.3 \%$ /year, HR $1.12 ; P=$ non-significant. Both edoxaban $60 \mathrm{mg}$ and $30 \mathrm{mg}$ were associated with a lower risk of major bleeding in both patients $<75$ years (edoxaban $60 \mathrm{mg}$; $2.5 \% /$ year vs $3.3 \%$ /year, absolute risk reduction $0.8 \%$ and edoxaban $30 \mathrm{mg}$ daily; 1.6\%/year vs 3.3\%/year, absolute risk reduction $1.7 \%$ ) and in patients $>75$ years (edoxaban $60 \mathrm{mg} ; 4 \%$ /year vs $4.8 \%$ /year, absolute risk reduction $0.8 \%$ and edoxaban $30 \mathrm{mg} ; 2.3 \%$ /year vs $4.8 \%$ /year, absolute risk reduction $2.6 \%$ ) when compared with warfarin. ${ }^{17}$

Overall, a favorable risk-benefit profile of all four NOACs when compared with warfarin was demonstrated by a meta-analysis including 71,683 subjects from the RE-LY, ROCKET-AF, ARISTOTLE, and ENGAGE AFTIMI 48 trials. The meta-analysis showed that DOACs reduced the risk of stroke and systemic thromboembolism by $19 \%$ (HR $0.81 ; 95 \%$ CI $[0.73-0.91] ; P<0.0001)$ with a $9 \%$ lower risk of major bleeding $(P=0.02) .{ }^{18}$ In patients aged $\geq 75$ years, DOACs resulted in a similar risk reduction in stroke and systemic thromboembolism (HR 0.78; 95\% CI [0.68-0.88]; $P=0.38$ ) compared with warfarin. DOACs were also associated with a similar risk of major bleeding in patients $<75$ years (HR 0.79 ; 95\% CI [0.67-0.94]; $P=0.28$ ) and in patients $>75$ years (HR 0.93 ; 95\% CI [0.74-1.17]; $P=0.28$ ) when compared with warfarin.
In AF patients unsuitable for warfarin, aspirin demonstrated a reduction of stroke and systemic thromboembolism by $20 \%$ when compared with placebo. ${ }^{19}$ The Apixaban Versus Acetylsalicylic Acid [ASA] to Prevent Stroke in Atrial Fibrillation Patients Who Have Failed or Are Unsuitable for Vitamin K Antagonist Treatment (AVERROES) trial was the only RCT comparing a DOAC (apixaban) with aspirin. The AVERROES trial included patients with a mean CHADS2 score of 2.0 and a mean age of 70 years. AVERROES showed that oral apixaban was associated with lower rate of stroke and systemic thromboembolism (1.6\%/year vs 3.7\%/year, HR $0.45 ; 95 \%$ CI [0.32-0.62]; $P<0.001)$ with similar rates of major bleeding when compared with aspirin $(1.4 \% /$ year vs $1.2 \%$ /year, HR 1.13 ; 95\% CI [0.74-1.75]; $P=0.57) .{ }^{20} \mathrm{In}$ patients aged $\geq 75$ years, apixaban demonstrated a trend toward lower rate of stroke and systemic thromboembolism with apixaban compared with aspirin (2\%/year vs $6.1 \%$ / year, $P=0.08)$. Apixaban was associated with a similar risk of major bleeding in patients $<75$ years $(0.9 \%$ /year vs $1 \%$ /year, $P=0.85)$ and in patients $>75$ years $(2.6 \% /$ year vs $2.2 \% /$ year, $P=0.85)$ when compared with aspirin.

These results suggest in age $\geq 75$ years apixaban is a viable alternative in patients unsuitable for warfarin.

In conclusion, in age $\geq 75$ years; NOACs have a favorable risk-benefit profile when compared with warfarin for prevention of stroke and systemic thromboembolism. Caution is recommended with dabigatran $150 \mathrm{mg}$ twice daily due to higher risk of major bleeding. There are no studies comparing one NOAC to another so determination of the safest NOAC in the elderly is based on indirect comparisons from studies of different patient populations.

\section{NOACs in patients with AF and CKD}

CKD is a major risk factor for AF and stroke with a two- to threefold increased risk with worsening kidney function. 1,21,22 CKD patients are also associated with a twofold increased risk of major bleeding. ${ }^{1,23-26}$ Despite this increased risk of stroke and systemic thromboembolism with CKD, it is not a part of the stroke stratifying risk score, CHA2DS2-VASc (Congestive heart failure, Hypertension, Age $\geq 65-74$ years: 1 point and $\geq 75$ years: 2 points, Diabetes, Stroke or transient ischemic attack, female sex, Vascular disease including peripheral vascular disease, aortic and coronary disease). ${ }^{27}$

The efficacy of OAC therapy for stroke prevention in CKD patients is not based on randomized prospective trials but the risk-benefit ratio is based on sub-analysis of clinical trials. ${ }^{19}$ A sub-analysis from the Stroke Prevention in Atrial Fibrillation (SPAF) 3 trials in patients with CKD stage III 
(eGFR [estimated glomerular filtration rate] 30-59 mL/min per $1.73 \mathrm{~kg} / \mathrm{m}^{2}$ ) demonstrated that OAC therapy with warfarin (international normalized ratio [INR] 2-3) reduced the risk of stroke and systemic thromboembolism when compared with aspirin and low dose warfarin. ${ }^{23}$

A net clinical benefit is defined as the difference between the perceived risk of stroke/systemic thromboembolism, mortality and major bleeding with OAC therapy. An analysis from the Danish registry including $11,128 \mathrm{CKD}$ patients not requiring dialysis, reported a net clinical benefit which was estimated including cardiovascular death, composite endpoint of hospitalization/death from stroke/bleeding; a composite endpoint of fatal stroke/fatal bleeding; and allcause death with warfarin when compared with placebo in AF with a CHA2DS2-VASc score $\geq 2 .{ }^{28}$

However, observational studies in patients with severe renal impairment and hemodialysis have raised questions regarding usage of oral warfarin. ${ }^{29-31}$ A prospective cohort study including 631 patients reported that patients with severe CKD (eGFR $<30 \mathrm{~mL} / \mathrm{min}$ per $1.73 \mathrm{~kg} / \mathrm{m}^{2}$ ) spent less time in therapeutic range (TTR) (INR 2-3), had a higher risk of over-anticoagulation (INR $>4, P=0.05$ ), and required lower warfarin dosing when compared with patients with an eGFR $>30 \mathrm{~mL} / \mathrm{min}$ per $1.73 \mathrm{~kg} / \mathrm{m} .^{2,32}$

The current ACC (American College of Cardiology)/ AHA (American Heart Association)/HRS (Heart Rhythm Society) guidelines on AF for stroke prevention suggests that adjusted dose warfarin (INR 2-3) may be used with severe CKD and hemodialysis. ${ }^{2}$ NOACs have also been approved by the US Food and Drug Administration (FDA) for stroke prevention from AF in CKD patients and in this section, the rationale for their use in $\mathrm{CKD}$ will be analyzed.

The ACC/AHA/HRS guidelines on AF for stroke prevention recommend dabigatran $150 \mathrm{mg}$ twice daily in patients with $\mathrm{CrCl}>30 \mathrm{~mL} / \mathrm{min}, 75 \mathrm{mg}$ twice daily in patients with a $\mathrm{CrCl} 15-30 \mathrm{~mL} / \mathrm{min}$, and is not recommended in patients with a $\mathrm{CrCl}<15 \mathrm{~mL} / \mathrm{min}$ or on hemodialysis. In the United States, dabigatran $110 \mathrm{mg}$ twice daily, a dose used in RE-LY, is not approved for use. ${ }^{2}$ Rivaroxaban $20 \mathrm{mg}$ daily is recommended in patients with a $\mathrm{CrCl}>50 \mathrm{~mL} / \mathrm{min}$ and $15 \mathrm{mg}$ daily in patients with a $\mathrm{CrCl} 15-50 \mathrm{~mL} / \mathrm{min}$. It is not recommended in patients with a $\mathrm{CrCl}<15 \mathrm{~mL} / \mathrm{min}$ or on hemodialysis. ${ }^{2}$ Apixaban $5 \mathrm{mg}$ twice daily and a reduced dose of $2.5 \mathrm{mg}$ twice daily is recommended if two of the three criteria are present: serum creatinine $\geq 1.5 \mathrm{mg} / \mathrm{dL}$, age $\geq 80$ years, body weight $\leq 60 \mathrm{~kg} .{ }^{2}$ Apixaban is currently not recommended by the guidelines in patients with a $\mathrm{CrCl}<25 \mathrm{~mL} / \mathrm{min}^{2}$ but has been approved by the FDA for patients on hemodialysis based on pharmacokinetic and pharmacodynamics studies. ${ }^{33}$

The ACC/AHA/HRS guidelines on AF for stroke prevention have not been updated since the FDA has approved edoxaban $60 \mathrm{mg}$ daily for patients with a $\mathrm{CrCl}>50 \mathrm{~mL} / \mathrm{min}$ to $\leq 95 \mathrm{~mL} / \mathrm{min}$ and a reduced dose of $30 \mathrm{mg}$ daily for patients with a $\mathrm{CrCl} 15-50 \mathrm{~mL} / \mathrm{min}^{2,34}$

The recommendation for dabigatran was based on the subgroup analysis of the RE-LY trial ${ }^{9}$ which included 3,505 patients with moderate $\mathrm{CKD}(\mathrm{CrCl} 30-49 \mathrm{~mL} / \mathrm{min})$ and excluded patients with severe $\mathrm{CKD}(\mathrm{CrCl}<30 \mathrm{~mL} / \mathrm{min})$. The study reported that compared with warfarin, dabigatran $150 \mathrm{mg}$ twice daily significantly reduced the rate of stroke and systemic thromboembolism (1.5\%/year vs $2.8 \%$ /year, $P<0.01)$. In terms of safety endpoints, major bleeding (5.44\%/year vs $5.51 \%$ /year, $P=0.12)$ was similar with dabigatran when compared with warfarin., ${ }^{9,24}$ The recommendation regarding the use of dabigatran $75 \mathrm{mg}$ twice daily in $\mathrm{CrCl}$ 15-30 $\mathrm{mL} / \mathrm{min}$ was based on pharmacological modeling studies. $^{2}$

To assess the safety of dabigatran in patients not involved in clinical trials an audit was conducted in New Zealand. Forty-four patients were treated with dabigatran $150 \mathrm{mg}$ twice daily for stroke prevention in AF. In this analysis 78 episodes of bleeding occurred, including 12 episodes of major bleeding over a period of 2 months, emphasizing the need for caution with dabigatran in elderly patients with poor kidney function. ${ }^{35}$

Of note $80 \%-85 \%$ of dabigatran is eliminated by the kidneys. With dabigatran, there is a 1.7-fold increase in exposure in patients with moderate $\mathrm{CKD}(\mathrm{CrCl}$ of $30-50 \mathrm{~mL} / \mathrm{min})$, however no dose adjustment is recommended. ${ }^{36}$ Hence fluctuations in $\mathrm{CrCl}$ can increase dabigatran plasma drug concentration increasing predisposition to bleeding, especially in the elderly patient. ${ }^{37}$ It is also recommended that dabigatran should be discontinued in acute renal failure to avoid drug toxicity and bleeding risk. ${ }^{36}$

The recommendation for use of rivaroxaban in CKD was based on analysis of the ROCKET-AF ${ }^{10}$ which included 2,950 patients with moderate $\mathrm{CKD}(\mathrm{CrCl} 30-49 \mathrm{~mL} / \mathrm{min})$. The study reported that compared with warfarin, rivaroxaban $15 \mathrm{mg}$ daily significantly reduced the rate of stroke and systemic thromboembolism (1.7\%/year vs $2.2 \%$ /year, $P<0.001)$. In terms of safety endpoints, major bleeding (4.49\%/year vs $4.70 \%$ /year, $P=0.5$ ) was similar with rivaroxaban when compared with warfarin. ${ }^{38}$ These results suggest a beneficial effect of rivaroxaban compared with warfarin in patients with $\mathrm{CKD}(\mathrm{CrCl} 30-49 \mathrm{~mL} / \mathrm{min})$. 
The recommendation for the use of rivaroxaban $15 \mathrm{mg}$ daily in patients with $\mathrm{CrCl} 15-30 \mathrm{~mL} / \mathrm{min}$ was based on drug plasma concentration studies. There are no clinical trials supporting the use of rivaroxaban in $\mathrm{CrCl}<30 \mathrm{~mL} / \mathrm{min}$ and in hemodialysis. 2,39

Of note $66 \%$ of rivaroxaban is eliminated by the kidneys. With rivaroxaban, there is a $12 \%$ increase in exposure in patients with moderate $\mathrm{CKD}(\mathrm{CrCl}$ of $30-49 \mathrm{~mL} / \mathrm{min})$ and a reduced dose of rivaroxaban $15 \mathrm{mg}$ daily is recommended. ${ }^{39}$ Fluctuations in $\mathrm{CrCl}$ can increase rivaroxaban plasma drug concentration increasing the predisposition to bleeding, especially in the elderly patient. It is also recommended that rivaroxaban be discontinued in acute renal failure to avoid drug toxicity and bleeding risk. ${ }^{39}$

The recommendation for use of apixaban in patients with CKD is based on analyses of the AVERROES and ARISTOTLE studies. AVERROES ${ }^{20}$ included 1,697 subjects with $\mathrm{CrCl}$ of $30-49 \mathrm{~mL} / \mathrm{min}$. The study reported that compared with aspirin, apixaban twice daily significantly reduced the rate of stroke and systemic thromboembolism (1.8\%/year vs $5.6 \% /$ year, $P<0.001)$. In terms of safety endpoints, major bleeding was similar with apixaban (3.2\%/year vs $2.5 \%$ year, $P=0.9$ ) when compared with aspirin. ${ }^{24}$ AVERROES also included 70 patients with a $\mathrm{CrCl} 15-29 \mathrm{~mL} / \mathrm{min}$ but no results have been published.

The ARISTOTLE trial ${ }^{11,40}$ included 3,017 subjects with $\mathrm{CrCl}$ of $25-50 \mathrm{~mL} / \mathrm{min}$. The study reported that compared with warfarin, apixaban twice daily had a similar rate of stroke and systemic thromboembolism (1.3\%/year vs $2.1 \% /$ year, $P=0.4$ ). In terms of safety endpoints, major bleeding was lower with apixaban (3.2\%/year vs 6.4\%/year, $P=0.03$ ) when compared with warfarin. The ARISTOTLE trial also included 270 subjects with $\mathrm{CrCl} 15-29 \mathrm{~mL} / \mathrm{min}$ but no results have been published. These results suggest that in $\mathrm{CKD}(\mathrm{CrCl} 25-50 \mathrm{~mL} / \mathrm{min})$ apixaban is an attractive alternative to warfarin.

Of note, $27 \%$ of apixaban is eliminated by the kidneys. ${ }^{33}$ Hence, fluctuations in $\mathrm{CrCl}$ in the absence of the other two characteristics (age $\geq 80$ years, body weight $\leq 60 \mathrm{~kg}$ ) do not require a dose reduction. ${ }^{33}$

The ACC/AHA/HRS guidelines on AF for stroke prevention have not been updated since the FDA has approved edoxaban $60 \mathrm{mg}$ daily for $\mathrm{CrCl}>50 \mathrm{~mL} / \mathrm{min}$ to $\leq 95 \mathrm{~mL} / \mathrm{min}$ and a reduced dose of $30 \mathrm{mg}$ daily for $\mathrm{CrCl} 15-50 \mathrm{~mL} / \mathrm{min} .^{2,34}$ The ENGAGE-TIMI 48 trial $^{12}$ compared a high intensity edoxaban therapy ( $60 \mathrm{mg}$ once daily, $30 \mathrm{mg}$ daily in patients with $\mathrm{CrCl}$ of $30-50 \mathrm{~mL} / \mathrm{min}$, body weight $<60 \mathrm{~kg}$ or coadministration of verapamil or quinidine) and a low intensity edoxaban (30 mg once daily, $15 \mathrm{mg}$ daily in patients with $\mathrm{CrCl}$ of $30-50 \mathrm{~mL} / \mathrm{min}$, body weight $<60 \mathrm{~kg}$ or concomitant use of verapamil or quinidine) to warfarin.

According to the FDA briefing document, in patients with a $\mathrm{CrCl} \geq 80 \mathrm{~mL} / \mathrm{min}$, there was a trend toward increased risk of stroke and systemic thromboembolism in the high intensity edoxaban group compared with warfarin (HR 1.1, 95\% CI [0.58-2.12]). The risk was substantially higher with edoxaban compared with warfarin in patients with a $\mathrm{CrCl}$ $>95 \mathrm{~mL} / \mathrm{min}$ (HR 2.16; 95\% CI [1.17, 3.97]) in patients with $\mathrm{CrCl} \geq 95 \mathrm{~mL} / \mathrm{min}$ when compared with warfarin. In patients with a $\mathrm{CrCl} 50-80 \mathrm{~mL} / \mathrm{min}$, the rate of stroke and systemic thromboembolism was similar with edoxaban when compared with warfarin $(1.49 \%$ /year vs $2.17 \%$ / year). In patients with a $\mathrm{CrCl} 30-50 \mathrm{~mL} / \mathrm{min}$, the rate of stroke and systemic thromboembolism was similar in both edoxaban and warfarin groups (2.34\%/year vs $2.70 \%$ /year). Patients with $\mathrm{CrCl}<30 \mathrm{~mL} / \mathrm{min}$ were excluded from the trial. The risk of major bleeding was substantially lower across all levels of $\mathrm{CrCl}$ with edoxaban than warfarin. ${ }^{41}$ These results suggest that in patients with moderate CKD $(\mathrm{CrCl} 30-50 \mathrm{~mL} / \mathrm{min}$ ) edoxaban is an attractive alternative to warfarin.

Of note, $50 \%$ of edoxaban is eliminated by the kidneys. In patients with moderate $\mathrm{CKD}(\mathrm{CrCl} \text { of } 30-50 \mathrm{~mL} / \mathrm{min})^{34}$ a reduced dose of edoxaban $30 \mathrm{mg}$ daily is recommended. Fluctuations in $\mathrm{CrCl}$ can increase edoxaban plasma drug concentration increasing predisposition to bleeding, especially in the elderly patient. ${ }^{34}$

In conclusion, in CKD NOACs have a similar risk-benefit profile in the prevention of stroke and systemic thromboembolism when compared with warfarin (Table 2). However, appropriate dose adjustment and close monitoring of kidney function is recommended (Table 3 ).

\section{NOACs in patients with AF and CAD}

$\mathrm{CAD}$ has a strong association with aging and also with AF due to overlapping cardiovascular risk factors. It is estimated that CAD occurs in $20 \%-45 \%$ of patients with concomitant AF. ${ }^{42}$ In this section we consider the use of anticoagulation in unstable and stable CAD.

Acute coronary syndromes (ACS) are usually due to plaque rupture and intracoronary thrombus formation. Treatment for this is usually with dual-antiplatelet therapy and parenteral anticoagulation. ${ }^{43,44}$ In theory, the use of DOACs in addition to these agents might offer additional benefit in patients following ACS. 
Table 2 Summary of risk of stroke/thromboembolism and major bleeding comparing direct oral anticoagulants and warfarin in patients with a $\mathrm{CrCl}<50 \mathrm{~mL} / \mathrm{min}$ and $>50 \mathrm{~mL} / \mathrm{min}$

\begin{tabular}{|c|c|c|c|c|}
\hline & \multicolumn{2}{|c|}{ Stroke/systemic thromboembolism (\%/year) } & \multicolumn{2}{|c|}{ Major bleeding (\%/year) } \\
\hline & $\mathrm{CrCl} 30-49 \mathrm{~mL} / \mathrm{min}$ & $\mathrm{CrCl} \geq 50-80 \mathrm{~mL} / \mathrm{min}$ & $\mathrm{CrCl} \mathrm{30-49} \mathrm{mL/min}$ & $\mathrm{CrCl} \geq 50-80 \mathrm{~mL} / \mathrm{min}$ \\
\hline \multicolumn{5}{|l|}{ RE-LY } \\
\hline Dabigatran $150 \mathrm{mg}$ & 1.5 & 1.2 & 5.4 & 3.3 \\
\hline Warfarin & 2.8 & 1.8 & 5.5 & 3.8 \\
\hline \multicolumn{5}{|l|}{ ROCKET-AF } \\
\hline Rivaroxaban & 1.7 & 1.6 & 4.5 & 3.2 \\
\hline Warfarin & 2.1 & 2 & 4.7 & 3.4 \\
\hline \multicolumn{5}{|l|}{ ARISTOTLE } \\
\hline Apixaban & $2.1^{*}$ & 1.2 & $3.2^{*}$ & 2.4 \\
\hline Warfarin & $2.7^{*}$ & 1.7 & $6.4^{*}$ & 3.2 \\
\hline \multicolumn{5}{|l|}{ ENGAGE-TIMI 48} \\
\hline Edoxaban & 2.3 & 1.5 & 3.8 & 3.1 \\
\hline Warfarin & 2.7 & 2.1 & 5.1 & 3.5 \\
\hline
\end{tabular}

Note: $* \mathrm{CrCl} 25-50 \mathrm{~mL} / \mathrm{min}$.

Abbreviations: $\mathrm{CrCl}$, creatinine clearance; RE-LY, Randomized Evaluation of Long-Term Anticoagulation Therapy; ROCKET-AF, Rivaroxaban Once Daily Oral Direct Factor Xa Inhibition Compared with Vitamin K Antagonism for Prevention of Stroke and Embolism Trial in Atrial Fibrillation; ARISTOTLE, Reduction in Stroke and Other Thromboembolic Events in Atrial Fibrillation trial; ENGAGE-TIMI 48, Effective Anticoagulation with Factor Xa Next Generation in Atrial Fibrillation-Thrombolysis in Myocardial Infarction 48 trial.

The ATLAS ACS-TIMI 46 (Anti-Xa Therapy to Lower Cardiovascular Events in Addition to Standard Therapy in Subjects with Acute Coronary Syndrome-Thrombolysis In Myocardial Infarction) trial ${ }^{45}$ examined rivaroxaban in addition to standard dual antiplatelet agents (DAPT) after ACS. When compared with standard care, the risk of myocardial infarction (MI), cardiovascular death, and stroke was reduced by $31 \%(P=0.027)$.

However in ATLAS ACS-TIMI 46 there was a dosedependent increased risk of bleeding compared with standard care (HR 2.21; 95\% CI [1.25-3.91] with $5 \mathrm{mg}$, 3.3; 95\% CI [2.31-4.87] with $10 \mathrm{mg}, 3.6$; 95\% CI [2.32-5.58] with $15 \mathrm{mg}$, and 5.0 ; 95\% CI [3.45-7.42] with $20 \mathrm{mg} ; P<0.0001$ ).

The ATLAS ACS-2 TIMI 51 trial examined rivaroxaban $5 \mathrm{mg}$ and $2.5 \mathrm{mg}$ daily in recent ACS patients. The results supported the earlier findings. Both doses of rivaroxaban reduced the risk of MI and cardiovascular mortality $(8.9 \% /$ year vs $10.7 \% /$ year, $P=0.008)$ with an increased rate of major bleeding (2.1\%/year vs $0.6 \% /$ year, $P<0.001){ }^{46}$

A subgroup analysis including ST-elevation MI (STEMI) patients also showed similar reduction in endpoint of cardiovascular death, MI, or stroke, compared with placebo $(8.4 \%$ /year vs $10.6 \%$ /year, $P=0.019)$ but a reduction in cardiovascular death was only seen with rivaroxaban $2.5 \mathrm{mg}$ $(2.2 \% /$ year vs $3.9 \% /$ year, $P=0.006)$, and not with rivaroxaban $5 \mathrm{mg}$. Both doses of rivaroxaban were associated with increased major bleeding $(2.2 \% /$ year vs $0.6 \%$ year, $P<0.001) .{ }^{47}$ Rivaroxaban $2.5 \mathrm{mg}$ twice daily in combination with standard DAPT is currently approved in Europe for ACS but not in the United States. ${ }^{48}$

Table 3 Dosing of direct oral anticoagulants in atrial fibrillation based on creatinine clearance

\begin{tabular}{|c|c|c|c|c|}
\hline & Dabigatran & Rivaroxaban & Apixaban & Edoxaban \\
\hline Normal renal function & I50 mg twice daily & 20 mg daily & $5 \mathrm{mg}$ twice daily or & 60 mg daily \\
\hline$(\mathrm{CrCl}>80 \mathrm{~mL} / \mathrm{min})$ & & & $2.5 \mathrm{mg}$ twice daily* & Avoid if $\mathrm{CrCl} \geq 95 \mathrm{~mL} / \mathrm{min}$ \\
\hline Mild renal impairment & I50 mg twice daily & 20 mg daily & $5 \mathrm{mg}$ twice daily or & 60 mg daily \\
\hline$(\mathrm{CrCl} 50-80$ mL/min) & & & $2.5 \mathrm{mg}$ twice daily* & \\
\hline Moderate renal impairment & I50 mg twice daily & 20 mg daily** & $5 \mathrm{mg}$ twice daily or & $60 \mathrm{mg}$ daily** or \\
\hline$(\mathrm{CrCl} 30-50 \mathrm{~mL} / \mathrm{min})$ & & I5 mg daily & $2.5 \mathrm{mg}$ twice daily* & 30 mg daily! \\
\hline $\begin{array}{l}\text { Severe renal impairment } \\
(\mathrm{CrCl}<30 \mathrm{~mL} / \mathrm{min})\end{array}$ & $75 \mathrm{mg}$ twice daily & I5 mg daily & Avoid & 30 mg daily! \\
\hline $\begin{array}{l}\text { Severe renal impairment } \\
\text { on hemodialysis }{ }^{+}\end{array}$ & Avoid & Avoid & $\begin{array}{l}5 \mathrm{mg} \text { twice daily or } \\
2.5 \mathrm{mg} \text { twice daily* }\end{array}$ & Avoid \\
\hline
\end{tabular}

Notes: *Apixaban $2.5 \mathrm{mg}$ daily if two patient characteristics including serum creatinine $\geq 1.5 \mathrm{mg} / \mathrm{dL}$, $\geq 80$ years, $\leq 60 \mathrm{~kg}$ are $\mathrm{present}$; $\mathrm{CrCl}$ I5-50 mL/min; **in CrCl $>50 \mathrm{~mL} / \mathrm{min}$; ${ }^{+}$no evidence from $\mathrm{RCTs}$ in $\mathrm{CrCl}<30 \mathrm{~mL} / \mathrm{min}$ and hemodialysis with dabigatran, rivaroxaban and edoxaban and $<25 \mathrm{~mL} / \mathrm{min}$ with apixaban. Abbreviations: $\mathrm{CrCl}$, creatinine clearance; $\mathrm{RCTs}$, randomized controlled trials. 
The results of other NOACs in ACS have not been as favorable as rivaroxaban. Studies examining apixaban in ACS consistently reported increased risk of major bleeding with no significant reduction in MI or cardiovascular mortality. ${ }^{49,50}$ Apixaban, with oral dosing of $2.5 \mathrm{mg}$ twice daily, $10 \mathrm{mg}$ daily, $10 \mathrm{mg}$ twice daily, and $20 \mathrm{mg}$ daily, was compared to placebo in recent STEMI and non-ST elevation MI patients on background DAPT in the Apixaban for Prevention of Acute Ischemic Events (APPRAISE) and APPRAISE-2 trials. ${ }^{49,50}$

The APPRAISE ${ }^{50}$ trial included 1,715 patients and reported a dose-dependent increased risk of major bleeding with oral apixaban $2.5 \mathrm{mg}$ twice daily (HR 1.78; 95\% CI, $0.91-3.48 ; P=0.09$ ) and $10 \mathrm{mg}$ once daily (HR $2.45 ; 95 \% \mathrm{CI}$, $1.31-4.61 ; P=0.005$ ) when compared with placebo. A nonsignificant trend toward reduction in ischemic outcomes was observed with apixaban $2.5 \mathrm{mg}$ twice daily (HR 0.73; 95\% [CI 0.44-1.19]; $P=0.09$ ) and $10 \mathrm{mg}$ daily groups (HR $0.61 ; 95 \%$ CI $[0.35-1.04] ; P=0.007)$ when compared with placebo.

A study examining edoxaban in ACS patients was planned and then delayed. Studies examining dabigatran in ACS reported increased bleeding risk and have raised concerns regarding an increased risk of MI. The Dabigatran vs placebo in patients with ACS on dual-antiplatelet therapy: a randomized, double-blind, Phase II trial (RE-DEEM) included patients after STEMI and non-ST elevation MI randomized to dabigatran vs placebo. The study demonstrated a dosedependent increased risk of major bleeding - HR 1.77; $95 \%$ CI (0.7-4.5), HR 2.17; 95\% CI (0.88-5.3), HR 3.9; 95\% CI (1.7-8.9) and HR 4.2; 95\% CI. At weeks 1 and 4, the coagulation activity measured by blood d-dimer levels were significantly decreased with all dabigatran doses by an average of 37 and $45 \%$ respectively $(P<0.001)$. Dabigatran $110 \mathrm{mg}(3 \%)$ and $150 \mathrm{mg}(3.5 \%)$ were also associated with fewer death, MI or stroke when compared with placebo (3.8\%). ${ }^{51}$

Studies reporting risk of MI with both ximelagatran and dabigatran have observed a numerically higher but not statistically increased risk of MI raising the suspicion of a class effect noted with direct thrombin inhibition., ${ }^{9,52-54}$ A lower risk of MI with both dabigatran $150 \mathrm{mg}$ (HR: 0.40, 95\% CI: $0.21-0.70)$ and dabigatran $110 \mathrm{mg}$ (HR: $0.30,95 \% \mathrm{CI}$ : 0.18-0.49) was also reported from a Danish registry including 13,914 AF patients when compared with warfarin. ${ }^{55}$ Another large "real-world" study including 134,414 Medicare patients showed no increased risk of MI with dabigatran when compared with warfarin (15.7\%/year vs $16.9 \%$ /year; HR 0.92 ; 95\% CI [0.78-1.08]; $P=0.29) .{ }^{56}$
Factor Xa inhibitors (rivaroxaban and apixaban) on the other hand did not show increased risk of major cardiovascular events when compared with placebo..$^{57-59}$

Observational studies have noted an increased risk of bleeding when ACS patients are treated with antiplatelet agents in addition to OAC therapy ${ }^{60,61}$ Combination of NOACs with aspirin reduced major adverse cardiovascular events by $30 \%$, but resulted in a $79 \%$ increase in major bleeding. Similarly, combination of DOACs with aspirin and clopidogrel decreased major adverse cardiovascular events by $13 \%$ but increased major bleeding by $134 \% .{ }^{61} \mathrm{~A}$ sub-analysis of the ENGAGE-TIMI 46 trial showed that edoxaban $30 \mathrm{mg}$ daily with aspirin was associated with a reduction in the net clinical outcome of cardiovascular death, stroke, and systemic thromboembolism or major bleeding (6.9\%/year vs $9.5 \%$ /year, $P=0.02$ ) when compared with warfarin..$^{62}$ The role of prasugrel and ticagrelor in the future and their bleeding risk when used in combination with DOACs for prevention of stroke and systemic thromboembolism and coronary events remains to be determined.

Warfarin is an effective agent to prevent MI. The Warfarin-Aspirin Reinfarction Study (WARIS II) included 3,630 patients after MI and demonstrated that warfarin was superior to aspirin in decreasing ischemic events following MI (16.7\%/year vs $20 \% /$ year, $P=0.03)$ but was associated with an increased rate of major bleeding $(0.62 \% /$ year vs $0.17 \%$ year, $P<0.001){ }^{63}$

Consequently for patients with stable $\mathrm{CAD}$ who remain free of ischemic events for $\geq 12$ months and $\mathrm{AF}$ and with CHA2DS2-VASc score $\geq 2$, warfarin may be reasonable.

The rate of MI was similar with rivaroxaban $(0.9 \% /$ year vs $1.1 \% /$ year; $P=0.12)$, apixaban $(0.5 \%$ vs $0.6 \%, P=0.4)$, and edoxaban $(60 \mathrm{mg}[0.7 \%$ vs $0.75 \%, P=0.13] ; 30 \mathrm{mg}$ dose $[0.9 \%$ vs $0.75 \%, P=0.13]$ ) when compared with warfarin in the ROCKET-AF, ${ }^{10}$ ARISTOTLE, ${ }^{11}$ and ENAGAGE TIMI-48 trials. ${ }^{12}$ This is where the use of DOACs, especially factor Xa inhibitors without aspirin seems favorable in stable $\mathrm{CAD}$. The use of dabigatran in patients with CAD is controversial and must take into account the favorable effects of stroke prevention with a possible increased incidence of MI. The concomitant use of aspirin, other P2Y12 inhibitors or combination therapy with NOACs may substantially increase risk of bleeding.

\section{NOACs and polypharmacy}

The term "polypharmacy" is defined as increased usage of prescription and non-prescription medications. Polypharmacy can be appropriate, especially in the elderly with 
chronic cardiovascular disease. However, polypharmacy can lead to various drug and dietary interactions leading to adverse or undesirable outcomes in patients, especially the elderly with AF. ${ }^{64}$

A recent analysis of the ROCKET-AF reported that $36 \%$ of the patients were on $0-4$ concomitant medications, $51 \%$ were on 5-9 concomitant medications, and $13 \%$ were on $\geq 10$ concomitant medications. Those who used $>10$ medications were older compared with those who used 0-4 medications (median age 75 years vs 71 years). Concomitant use of a higher number of medications ( $>10$ medications) showed a trend toward increased risk of major and minor bleeding (HR 1.46, 95\% CI [1.29-1.64], $P=0.81$ ) but not stroke and systemic thromboembolism when compared to use of $0-4$ medications. ${ }^{65}$ Another cross-sectional study from the Danish anticoagulation clinic reported that $53 \%$ of patients used $\geq 5$ prescription medications. ${ }^{66}$

Hence, it is important for the prescribing physician to be aware of the various drug interactions that may increase or decrease drug plasma concentration of any OAC therapy as a decrease in drug plasma concentration decreases efficacy for prevention of stroke and systemic thromboembolism while an increase in drug plasma concentration may increase the risk of major bleeding (Table 4).

Historically, warfarin has been the oral anticoagulant of choice for stroke prevention in AF. However, warfarin has several limitations especially in the elderly with polypharmacy due to its complex pharmacokinetics and pharmacodynamic properties, narrow therapeutic window, and several drug interactions. The interactions between warfarin and other drugs have been reviewed extensively by other manuscripts and are beyond the scope of this paper. NOACs on the other hand appear to have a more stable pharmacodynamic profile and fewer drug interactions than warfarin making them more favorable in the setting of polypharmacy. However, certain groups of drugs can cause significant drug interaction with DOACs, thereby altering drug plasma concentration and must be avoided.

All the NOACs are substrates of the P-gp transport system. P-gp functions as a transmembrane efflux pump which moves the substrates from inside to outside the cell. Drugs which induce or inhibit the P-gp system have a significant therapeutic effect on the DOACs.

Strong P-gp inducers such as phenytoin and carbamazepine which are typically used as anti-seizure medications in elderly can reduce dabigatran drug plasma concentration and hence must be avoided. Rifampin, an anti-infective medication, also a strong P-gp inducer must be avoided due to similar reasons. ${ }^{36}$

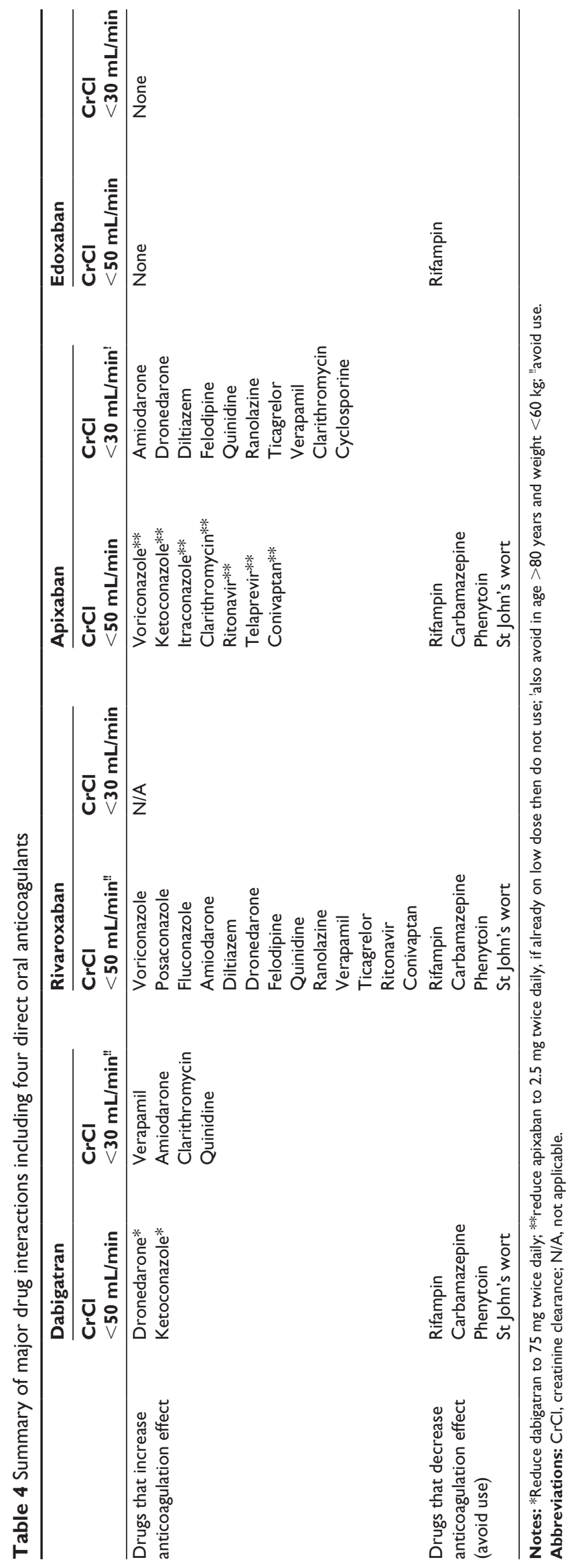


Certain antiarrhythmic medications such as dronedarone and rate controlling agents like verapamil which are used in patients with AF can increase dabigatran drug plasma concentration and mean area under the curve (AUC). It is recommended that dabigatran is administered 2 hours apart from these agents..$^{36}$ Ketoconazole is a commonly used antifungal medication in the elderly which is also a strong P-gp inhibitor and must be spaced 2 hours apart with dabigatran. ${ }^{36} \mathrm{~A}$ dose reduction of dabigatran $75 \mathrm{mg}$ twice daily is recommended with concomitant use of dronedarone or ketoconazole in patients with a $\mathrm{CrCl}<50 \mathrm{~mL} / \mathrm{min}$.

Dose adjustment of dabigatran is not necessary in the elderly with commonly used drugs such as amiodarone, verapamil, quinidine, digoxin, clarithromycin, diclofenac, proton pump inhibitors, and $\mathrm{H} 2$ antagonists in patients with normal kidney function. However, it is recommended to avoid usage of dabigatran with $\mathrm{CrCl}<30 \mathrm{~mL} / \mathrm{min}^{36,37}$

Elderly patients may be treated with aspirin and clopidogrel for secondary prevention of cardiovascular events. Clopidogrel loading $300 \mathrm{mg}$ or $600 \mathrm{mg}$ demonstrated a $40 \%$ increase in mean dabigatran drug plasma concentration and a $30 \%$ increase in mean dabigatran AUC. However, no change in dosing regimen is recommended. ${ }^{36,67}$ Administration of $180 \mathrm{mg}$ loading dose of ticagrelor demonstrated a $65 \%$ increase in mean drug plasma concentration and a $49 \%$ increase in mean dabigatran AUC. The packet insert recommends that ticagrelor be given 2 hours apart from dabigatran to decrease drug plasma concentration, AUC, and bleeding risk from similar reasons. Due to lack of sufficient data and because of increased platelet inhibition with prasugrel and ticagrelor with increased risk of bleeding, it may be reasonable to avoid prasugrel and ticagrelor with DOACs due to increased risk of bleeding.

Non-steroidal anti-inflammatory drugs (NSAIDs) are commonly used in elderly patients for a variety of reasons. No change in dosing is recommended with dabigatran. However, NSAIDs must be used with caution with all NOACs as they are reported to increase risk of major bleeding and stroke and systemic thromboembolism with AF. ${ }^{68}$

Rivaroxaban is metabolized by CYP3A4, CYP3A5, and CYP2J2 as well as CYP independent hepatic mechanisms. ${ }^{69}$ Apixaban is metabolized by CYP3A4 with minor involvement of CYP1A2, CYP2C8, CYP2C9, and CYP2J2. ${ }^{70}$ Edoxaban is metabolized by CYP3A $4 .{ }^{71}$ The possibility of interaction with other drugs that are substrates or inducers of CYP including antihypertensives, anti-arrhythmics, antiischemic, and anti-infective agents must be entertained, particularly in the elderly. Strong CYP 3A4 and P-gp inhibitors such as all "azoles", ritonavir, amiodarone, dronedarone, ranolazine, felodipine, and conivaptan must be avoided with rivaroxaban in $\mathrm{CrCl}<50 \mathrm{~mL} / \mathrm{min}^{39}$

All "azoles", ritonavir, clarithromycin, and conivaptan must be avoided with apixaban in patients in whom a reduced dose of apixaban is recommended. A dose reduction to apixaban $2.5 \mathrm{mg}$ is recommended in whom a dose of apixaban $5 \mathrm{mg}$ twice daily is recommended..$^{33}$ It is also recommended to avoid concomitant use of rivaroxaban and apixaban with drugs that are combined P-gp and strong CYP3A4 inducers which may be used in elderly as anti-seizure medications (carbamazepine, phenytoin), antidepressants (St John's wort), and anti-infective (rifampin) agents. The edoxaban package insert reports that edoxaban does not inhibit the major cytochrome 450 enzymes; although it should not be used with rifampin. Diltiazem, which is commonly used as a rate control strategy in elderly with $\mathrm{AF}$ is a moderate CYP3A4 and P-gp inhibitor and can increase the mean drug plasma concentration of rivaroxaban in patients with a $\mathrm{CrCl}<50 \mathrm{~mL} / \mathrm{min}$ and apixaban in $\mathrm{CrCl}<30 \mathrm{~mL} / \mathrm{min}$ and must be used with caution. ${ }^{33}$

Agents such as aspirin and clopidogrel have demonstrated prolonged bleeding time and should be avoided if possible. ${ }^{72,73}$ Excess bleeding was observed during the administration of rivaroxaban with NSAIDs. ${ }^{74}$ Edoxaban AUC increased with co-administration of P-gp inhibitors such as verapamil, dronedarone, amiodarone, and quinidine by $29 \%, 84 \%$, $40 \%$, and $76 \%$. Edoxaban also increased mean drug plasma concentration when concomitantly administered with digoxin by $28 \%$; however, the AUC was not affected. ${ }^{75}$ The edoxaban package insert does not currently recommend a dose adjustment with concomitant use of the above P-gp inhibitors. ${ }^{34}$ Co-administration of anticoagulants, antiplatelet drugs, and thrombolytics with all three factor Xa inhibitors increases the risk of bleeding and must be used with caution. ${ }^{76}$

Overall, in elderly patients with polypharmacy NOACs appear to be more favorable than warfarin for stroke prevention in AF. However, each of these NOACs has their own set of drug interactions and must be customized by the prescribing physician based on other patient prescription medications to maximize benefit.

\section{NOACs and frailty}

Frailty is defined as a decline in functional and physiological reserve associated with aging, in the presence of concomitant chronic medical problems; it is characterized by cognitive impairment, restricted mobility, fall risk, low bodyweight (LBW), malnutrition, and inability to cope with various 


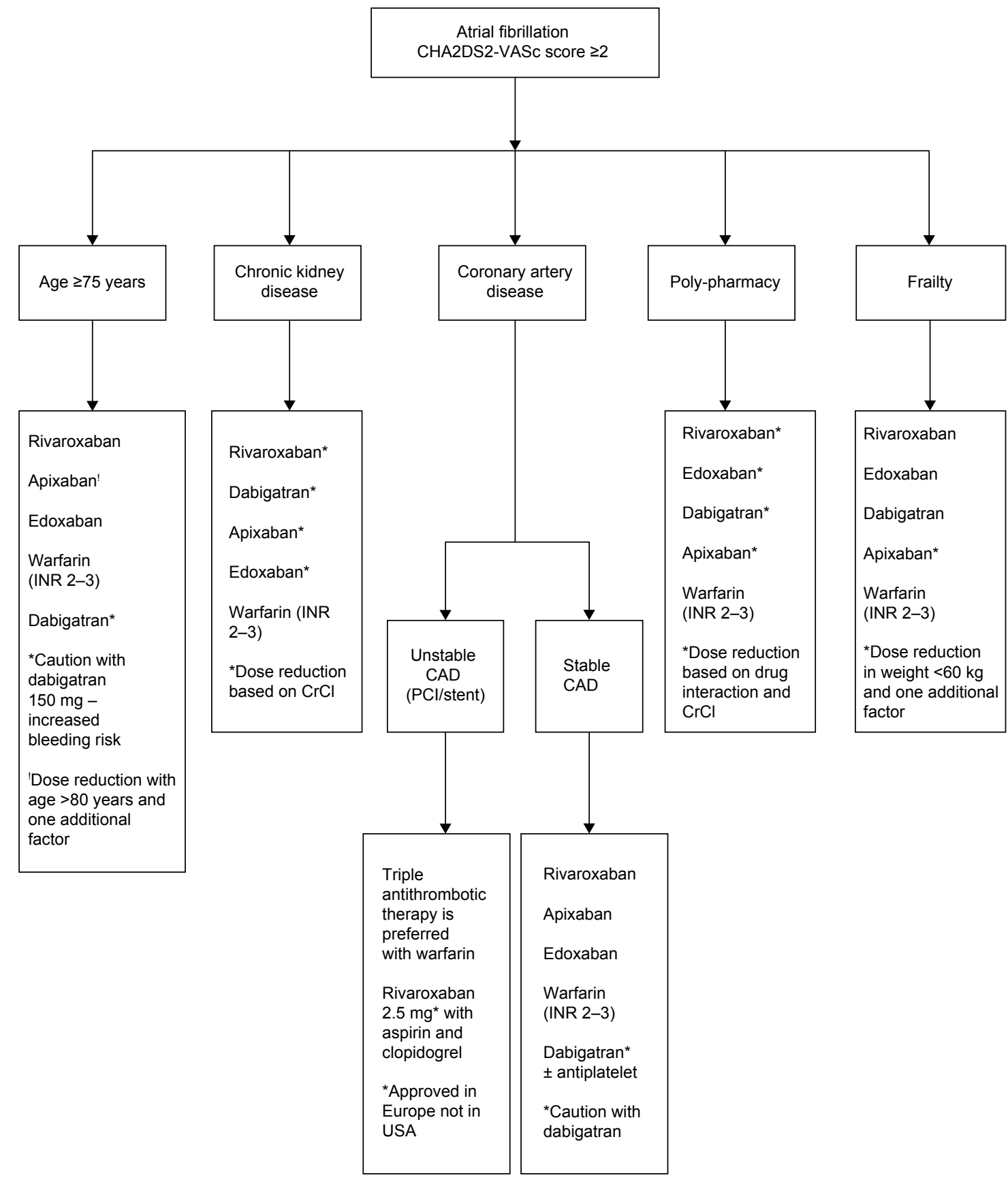

Figure I Summary of choice of oral anticoagulants in elderly with various comorbidities.

Abbreviations: CHA2DS2-VASc, Congestive heart failure, Hypertension, Age $\geq 65-74$ years: I point and $\geq 75$ years: 2 points, Diabetes, Stroke or transient ischemic attack, female sex, Vascular disease including peripheral vascular disease, aortic and coronary disease; $\mathrm{CrCl}$, creatinine clearance; CAD, coronary artery disease; $\mathrm{PCl}$, percutaneous coronary intervention; INR, international normalized ratio.

stressors in life. ${ }^{77}$ The American Society of Geriatrics recommends a scoring index to stratify frailty in elderly based on unintentional $>10 \mathrm{lb}$ weight loss in 1 year, slow walking speed, low physical activity, weakness, and exhaustion. ${ }^{78}$ Recent studies have demonstrated that AF may be a risk factor for frailty in the elderly population. ${ }^{79-81}$

The association between frailty, stroke, and cognitive impairment was demonstrated by a 7-year prospective study including 5,480 individuals aged between 65 and 95 years, which reported that frailty was associated with vascular dementia but not with other types of dementia. ${ }^{82}$ Despite the increased stroke risk frailty is one of the most common reasons to withhold OAC therapy ${ }^{83-85} \mathrm{~A}$ prospective cohort study including 220 elderly AF patients aged $\geq 70$ years reported that frail patients were less likely to receive OAC therapy during hospitalization and were also at a higher risk 
of stroke (HR 3.5, 95\% CI 1.0-12.0) and mortality (HR $2.8,95 \%$ CI 1.2-6.5) at 6 months follow-up than non-frail patients. ${ }^{85}$ Currently the ACC/AHA/HRS AF guidelines do not provide specific recommendations on usage of OAC therapy in frail elderly patients. ${ }^{2}$

Although warfarin is a very effective medication for stroke prevention in AF, there may be several challenges in administering and monitoring the medication. The TTR, an important measure of the quality of anticoagulation, is lower in patients with cognitive dysfunction. An analysis from The Atrial Fibrillation Clopidogrel Trial With Irbesartan for Prevention of Vascular Events (ACTIVE) investigators reported that a mini mental status exam (MMSE) score $<26$ was associated with higher vascular events $(6.7 \%$ vs $3.6 \% / 100$ patient-years) and bleeding risk ( $9.6 \%$ vs $7 \% / 100$ patientyears) in comparison to MMSE score $>26 .{ }^{86}$ Decreased TTR with warfarin was also associated with a low MMSE (TTE of $<25 \%$ : HR 5.34; TTR of 26\%-50\%: HR 4.10; and TTR of $51 \%-75 \%$ : HR $=2.57) .{ }^{87}$

All the NOACs may be favorable options in elderly frail individuals with cognitive decline as they overcome some of the limitations of warfarin such as fixed dosing, steady pharmacokinetics, and lack of coagulation monitoring. However, it is important to assess patient compliance and adherence with all the DOACs, since if a patient misses several doses due to cognitive dysfunction they will no longer be protected due to the short half-life of the drug. Rivaroxaban and edoxaban have the advantage of being a once a day medication when compared to dabigatran and apixaban.

Mobility and fall risk are important factors which are commonly cited reasons for withholding OAC therapy in frail elderly patients. However, it has been difficult to correlate major bleeding with high risk of falls and is often overstated in elderly frail patients. ${ }^{88-90}$ Fall risk can be assessed by tools such as Identification of Seniors at Risk score, Get Up and Go Test, Activities of Daily Living, and Instrumental Activities of Daily Living by the prescribing physician prior to initiation of OAC therapy and thereafter on each subsequent clinic visit. ${ }^{91} \mathrm{OAC}$ therapy should not be withheld in elderly patients with risk of stroke and systemic thromboembolism. Both warfarin and NOACs are effective and the choice must be dictated by careful risk-benefit analysis.

Intracranial bleed remains the most feared complication in an elderly patient on OAC therapy with fall risk. A recent pooled analysis of RCTs including 57,491 AF patients reported that NOACs reduced risk of intracranial bleed by $41 \%$ when compared to traditional therapy (warfarin and aspirin). ${ }^{92}$ All the four RCTs (RE-LY, ROCKET-AF,
ARISTOTLE, ENGAGE-TIMI 46) involving NOACs have also demonstrated significantly lower rate of major bleeding, especially intracranial bleeding. ${ }^{9-12}$ The lack of antidote in the event of a fall resulting in major bleeding remains a drawback with all NOACs of which the prescribing physician must be cautious. Overall, the benefits of DOACs appear to outweigh the risks when compared to warfarin for stroke prevention in AF in elderly frail patients at risk of fall.

LBW and low body mass index are common characteristics of frailty in elderly patients with multiple comorbidities. ${ }^{93}$ Pharmacokinetic studies have demonstrated no variation in peak dabigatran drug plasma concentration in underweight patients $(\leq 50 \mathrm{~kg})^{94}$ while rivaroxaban drug plasma concentration increased by $24 \%$ with no change in AUC. Hence no change in dosing is recommended. ${ }^{95}$ Weight $\leq 60 \mathrm{~kg}$ was one of the criteria for reduced edoxaban (30 mg daily) dosing and one of the two criteria for reduced apixaban (2.5 mg twice daily) dosing. ${ }^{9,11,12}$ Furthermore, DOACs have minimal dietary interactions when compared with warfarin and may be preferred in a frail elderly patient with several dietary restrictions. NOACs may remain the drug of choice in patients with LBW but caution is recommended due to limited clinical data regarding the safety and efficacy of NOACs in underweight patients as only a small proportion of such patients are enrolled in RCTs.

Limited life expectancy is another important consideration at the time of initiation of OAC therapy for stroke prevention in AF in an elderly frail patient. Unfortunately, there are no studies to guide clinicians regarding appropriate therapy for stroke prevention in patients with limited life expectancy ( $\leq 6$ months) and must be based on an informed decision between the physicians, patient, and caregiver. A multidimensional prognostic index derived from the comprehensive geriatric assessment can be a useful tool to stratify patients both for 6-month and 1-year mortality in addition to the other stroke and bleeding risk tools prior to starting OAC therapy. ${ }^{96}$ NOACs have the advantage of fixed dosing and lack of coagulation monitoring avoiding the need for unnecessary blood draws and frequent visits to the coagulation clinic in a patient with limited life expectancy. Rivaroxaban and edoxaban appear favorable due to once a day dosing.

In conclusion, the management of elderly AF patients with frailty requires a multidisciplinary approach. NOACs appear promising and help overcome some if not all of the warfarin deficiencies. However, further research is necessary to establish the safety and efficacy of NOACs for stroke prevention in this vulnerable population. 


\section{Conclusion}

Stroke prevention in elderly (age $\geq 75$ years) AF patients remains a challenge due to high risk of stroke, systemic thromboembolism, and bleeding. Despite several important advantages with NOACs, its use in an elderly patient with multiple comorbidities is limited (Figure 1). Prior to considering OAC therapy in an elderly frail patient, a comprehensive assessment including the risks and benefits, stroke risk (CHA2DS2-VASc score), baseline kidney function $(\mathrm{CrCl})$, cognitive status (MMSE), mobility (Activities of Daily Living) and fall risk (Identification of Seniors at Risk score), polypharmacy, body weight/body mass index, nutritional status assessment, and life expectancy (multidimensional prognostic index) should be determined.

\section{Disclosure}

MK Turagam and P Velagapudi have no conflicts of interest to disclose. GC Flaker is a consultant for Bristol-Myers Squibb, Pfizer, Janssen, and Daiichi-Sanyko.

\section{References}

1. Go AS, Hylek EM, Phillips KA, et al. Prevalence of diagnosed atrial fibrillation in adults: national implications for rhythm management and stroke prevention: the AnTicoagulation and Risk Factors in Atrial Fibrillation (ATRIA) Study. JAMA. 2001;285(18):2370-2375.

2. January CT, Wann LS, Alpert JS, et al. 2014 AHA/ACC/HRS guideline for the management of patients with atrial fibrillation: a report of the American College of Cardiology/American Heart Association Task Force on Practice Guidelines and the Heart Rhythm Society. J Am Coll Cardiol. 2014;64(21):e1-e76.

3. Hylek EM, D’Antonio J, Evans-Molina C, Shea C, Henault LE, Regan S. Translating the results of randomized trials into clinical practice: the challenge of warfarin candidacy among hospitalized elderly patients with atrial fibrillation. Stroke. 2006;37(4):1075-1080.

4. Lloyd-Jones DM, Wang TJ, Leip EP, et al. Lifetime risk for development of atrial fibrillation: the Framingham Heart Study. Circulation. 2004;110(9): 1042-1046.

5. Miyasaka Y, Barnes ME, Gersh BJ, et al. Secular trends in incidence of atrial fibrillation in Olmsted County, Minnesota, 1980 to 2000, and implications on the projections for future prevalence. Circulation. 2006;114(2): 119-125.

6. Go AS, Mozaffarian D, Roger VL, et al. Heart disease and stroke statistics - 2014 update: a report from the American Heart Association. Circulation. 2014;129(3):e28-e292.

7. Coppens M, Eikelboom JW, Hart RG, et al. The CHA2DS2-VASc score identifies those patients with atrial fibrillation and a CHADS2 score of 1 who are unlikely to benefit from oral anticoagulant therapy. Eur Heart J. 2013;34(3):170-176.

8. Lip GY, Clementy N, Pericart L, Banerjee A, Fauchier L. Stroke and major bleeding risk in elderly patients aged $\geq 75$ years with atrial fibrillation: the Loire Valley atrial fibrillation project. Stroke. 2015;46(1): $143-150$.

9. Connolly SJ, Ezekowitz MD, Yusuf S, et al. Dabigatran versus warfarin in patients with atrial fibrillation. $N$ Engl J Med. 2009;361(12): 1139-1151.

10. Patel MR, Mahaffey KW, Garg J, et al. Rivaroxaban versus warfarin in nonvalvular atrial fibrillation. $N$ Engl J Med. 2011;365(10):883-891.

11. Granger CB, Alexander JH, McMurray JJ, et al. Apixaban versus warfarin in patients with atrial fibrillation. $N$ Engl J Med. 2011;365(11): 981-992.
12. Giugliano RP, Ruff CT, Braunwald E, et al. Edoxaban versus warfarin in patients with atrial fibrillation. $N$ Engl J Med. 2013;369(22): 2093-2104.

13. Eikelboom JW, Wallentin L, Connolly SJ, et al. Risk of bleeding with 2 doses of dabigatran compared with warfarin in older and younger patients with atrial fibrillation: an analysis of the randomized evaluation of long-term anticoagulant therapy (RE-LY) trial. Circulation. 2011;123(21): 2363-2372.

14. Halperin JL, Hankey GJ, Wojdyla DM, et al. Efficacy and safety of rivaroxaban compared with warfarin among elderly patients with nonvalvular atrial fibrillation in the Rivaroxaban Once Daily, Oral, Direct Factor Xa Inhibition Compared With Vitamin K Antagonism for Prevention of Stroke and Embolism Trial in Atrial Fibrillation (ROCKET AF). Circulation. 2014;130(2):138-146.

15. Halvorsen S, Atar D, Yang H, et al. Efficacy and safety of apixaban compared with warfarin according to age for stroke prevention in atrial fibrillation: observations from the ARISTOTLE trial. Eur Heart J. 2014;35(28): 1864-1872.

16. Lopes RD, Al-Khatib SM, Wallentin L, et al. Efficacy and safety of apixaban compared with warfarin according to patient risk of stroke and of bleeding in atrial fibrillation: a secondary analysis of a randomised controlled trial. Lancet. 2012;380(9855):1749-1758.

17. Toda Kato E, Giugliano RP, RuffCT, et al. Abstract 16612: Efficacy and Safety of Edoxaban for the Management of Elderly Patients With Atrial Fibrillation: Engage AF-TIMI 48. Circulation. 2014;130:A16612.

18. Ruff CT, Giugliano RP, Braunwald E, et al. Comparison of the efficacy and safety of new oral anticoagulants with warfarin in patients with atrial fibrillation: a meta-analysis of randomised trials. Lancet. 2014;383(9921): 955-962.

19. Hart RG, Pearce LA, Aguilar MI. Meta-analysis: antithrombotic therapy to prevent stroke in patients who have nonvalvular atrial fibrillation. Ann Intern Med. 2007;146(12):857-867.

20. Connolly SJ, Eikelboom J, Joyner C, et al. Apixaban in patients with atrial fibrillation. $N$ Engl J Med. 2011;364(9):806-817.

21. Soliman EZ, Prineas RJ, Go AS, et al. Chronic kidney disease and prevalent atrial fibrillation: the Chronic Renal Insufficiency Cohort (CRIC). Am Heart J. 2010;159(6):1102-1107.

22. Baber U, Howard VJ, Halperin JL, et al. Association of chronic kidney disease with atrial fibrillation among adults in the United States: REasons for Geographic and Racial Differences in Stroke (REGARDS) Study. Circ Arrhythm Electrophysiol. 2011;4(1):26-32.

23. Hart RG, Pearce LA, Asinger RW, Herzog CA. Warfarin in atrial fibrillation patients with moderate chronic kidney disease. Clin J Am Soc Nephrol. 2011;6(11):2599-2604.

24. Eikelboom JW, Connolly SJ, Gao P, et al. Stroke risk and efficacy of apixaban in atrial fibrillation patients with moderate chronic kidney disease. J Stroke Cerebrovasc Dis. 2012;21(6):429-435.

25. Piccini JP, Stevens SR, Chang Y, et al. Renal dysfunction as a predictor of stroke and systemic embolism in patients with nonvalvular atrial fibrillation: validation of the R(2)CHADS(2) index in the ROCKET AF (Rivaroxaban Once-daily, oral, direct factor Xa inhibition Compared with vitamin $\mathrm{K}$ antagonism for prevention of stroke and Embolism Trial in Atrial Fibrillation) and ATRIA (AnTicoagulation and Risk factors In Atrial fibrillation) study cohorts. Circulation. 2013;127(2): 224-232.

26. Bos MJ, Koudstaal PJ, Hofman A, Breteler MM. Decreased glomerular filtration rate is a risk factor for hemorrhagic but not for ischemic stroke: the Rotterdam Study. Stroke. 2007;38(12):3127-3132.

27. Olesen JB, Lip GY, Hansen ML, et al. Validation of risk stratification schemes for predicting stroke and thromboembolism in patients with atrial fibrillation: nationwide cohort study. BMJ. 2011;342:d124.

28. Bonde AN, Lip GY, Kamper AL, et al. Net clinical benefit of antithrombotic therapy in patients with atrial fibrillation and chronic kidney disease: a nationwide observational cohort study. J Am Coll Cardiol. 2014;64(23): 2471-2482.

29. Chan KE, Lazarus JM, Thadhani R, Hakim RM. Warfarin use associates with increased risk for stroke in hemodialysis patients with atrial fibrillation. J Am Soc Nephrol. 2009;20(10):2223-2233. 
30. Elliott MJ, Zimmerman D, Holden RM. Warfarin anticoagulation in hemodialysis patients: a systematic review of bleeding rates. $\mathrm{Am} \mathrm{J}$ Kidney Dis. 2007;50(3):433-440.

31. Chan KE, Lazarus JM, Thadhani R, Hakim RM. Anticoagulant and antiplatelet usage associates with mortality among hemodialysis patients. J Am Soc Nephrol. 2009;20(4):872-881.

32. Limdi NA, Beasley TM, Baird MF, et al. Kidney function influences warfarin responsiveness and hemorrhagic complications. J Am Soc Nephrol. 2009;20(4):912-921.

33. Eliquis ${ }^{\circledR}$ (apixaban) tablets for oral use [prescribing information]. Princeton, NJ: Bristol-Myers Squibb; 2012.

34. Savaysa ${ }^{\circledR}$ (edoxaban) tablets for oral use [prescribing information] Parsipanny, NJ: Daiichi Sankyo, Inc; 2015.

35. Harper P, Young L, Merriman E. Bleeding risk with dabigatran in the frail elderly. $N$ Engl J Med. 2012;366(9):864-866.

36. Pradaxa ${ }^{\circledR}$ (dabigatran etexilate mesylate) capsules for oral use [prescribing information]. Ridgefield, CT: Boehringer Ingelheim Pharmaceuticals, Inc.; 2015.

37. Stangier J, Rathgen K, Stahle H, Mazur D. Influence of renal impairment on the pharmacokinetics and pharmacodynamics of oral dabigatran etexilate: an open-label, parallel-group, single-centre study. Clin Pharmacokinet. 2010;49(4):259-268.

38. Fox KA, Piccini JP, Wojdyla D, et al. Prevention of stroke and systemic embolism with rivaroxaban compared with warfarin in patients with non-valvular atrial fibrillation and moderate renal impairment. Eur Heart J. 2011;32(19):2387-2394.

39. Xarelto ${ }^{\circledR}$ (rivaroxaban) tablets for oral use [prescribing information] Leverkusen, Germany: Bayer Pharma AG; 2014.

40. Hohnloser SH, Hijazi Z, Thomas L, et al. Efficacy of apixaban when compared with warfarin in relation to renal function in patients with atrial fibrillation: insights from the ARISTOTLE trial. Eur Heart J. 2012; 33(22):2821-2830.

41. US Food and Drug Administration. FDA Draft Briefing Document for the Cardiovascular and Renal Drugs Advisory Committee (CRDAC). FDA; 2014. Available from: http://www.fda.gov/ downloads/AdvisoryCommittees/CommitteesMeetingMaterials/Drugs/ CardiovascularandRenalDrugsAdvisoryCommittee/UCM420704.pdf. Accessed July 20, 2015.

42. AFFIRM Investigators. Atrial Fibrillation Follow-up Investigation of Rhythm Management. Baseline characteristics of patients with atrial fibrillation: the AFFIRM Study. Am Heart J. 2002;143(6):991-1001.

43. American College of Emergency Physicians; Society for Cardiovascular Angiography and Interventions, O’Gara PT, et al. 2013 ACCF/AHA guideline for the management of ST-elevation myocardial infarction: a report of the American College of Cardiology Foundation/American Heart Association Task Force on Practice Guidelines. J Am Coll Cardiol. 2013;61(4):e78-e140.

44. Anderson JL, Adams CD, Antman EM, et al. 2012 ACCF/AHA focused update incorporated into the ACCF/AHA 2007 guidelines for the management of patients with unstable angina/non-ST-elevation myocardial infarction: a report of the American College of Cardiology Foundation/ American Heart Association Task Force on Practice Guidelines. J Am Coll Cardiol. 2013;61(23):e179-e347.

45. Mega JL, Braunwald E, Mohanavelu S, et al. Rivaroxaban versus placebo in patients with acute coronary syndromes (ATLAS ACS-TIMI 46): a randomised, double-blind, phase II trial. Lancet. 2009;374(9683):29-38.

46. Mega JL, Braunwald E, Wiviott SD, et al. Rivaroxaban in patients with a recent acute coronary syndrome. $N$ Engl J Med. 2012;366(1):9-19.

47. Mega JL, Braunwald E, Murphy SA, et al. Rivaroxaban in patients stabilized after a ST-segment elevation myocardial infarction: results from the ATLAS ACS-2-TIMI-51 trial (Anti-Xa Therapy to Lower Cardiovascular Events in Addition to Standard Therapy in Subjects with Acute Coronary Syndrome-Thrombolysis In Myocardial Infarction-51). J Am Coll Cardiol. 2013;61(18):1853-1859.

48. Task Force on the management of STseamiotESoC, Steg PG, James SK, et al. ESC Guidelines for the management of acute myocardial infarction in patients presenting with ST-segment elevation. Eur Heart J. 2012;33(20):2569-2619.
49. Alexander JH, Lopes RD, James S, et al. Apixaban with antiplatelet therapy after acute coronary syndrome. $N$ Engl J Med. 2011;365(8): 699-708.

50. APPRAISE Steering Committee and Investigators, Alexander JH, Becker RC, Apixaban, an oral, direct, selective factor Xa inhibitor, in combination with antiplatelet therapy after acute coronary syndrome: results of the Apixaban for Prevention of Acute Ischemic and Safety Events (APPRAISE) trial. Circulation. 2009;119(22):2877-2885.

51. Oldgren J, Budaj A, Granger CB, et al. Dabigatran vs. placebo in patients with acute coronary syndromes on dual antiplatelet therapy: a randomized, double-blind, phase II trial. Eur Heart J. 2011;32(22): 2781-2789.

52. Hohnloser SH, Oldgren J, Yang S, et al. Myocardial ischemic events in patients with atrial fibrillation treated with dabigatran or warfarin in the RE-LY (Randomized Evaluation of Long-Term Anticoagulation Therapy) trial. Circulation. 2012;125(5):669-676.

53. Uchino K, Hernandez AV. Dabigatran association with higher risk of acute coronary events: meta-analysis of noninferiority randomized controlled trials. Arch Intern Med. 2012;172(5):397-402.

54. Artang R, Rome E, Nielsen JD, Vidaillet HJ. Meta-analysis of randomized controlled trials on risk of myocardial infarction from the use of oral direct thrombin inhibitors. Am J Cardiol. 2013;112(12): 1973-1979.

55. Larsen TB, Rasmussen LH, Skjoth F, et al. Efficacy and safety of dabigatran etexilate and warfarin in "real-world" patients with atrial fibrillation: a prospective nationwide cohort study. J Am Coll Cardiol. 2013;61(22): 2264-2273.

56. Graham DJ, Reichman ME, Wernecke M, et al. Cardiovascular, bleeding, and mortality risks in elderly Medicare patients treated with dabigatran or warfarin for nonvalvular atrial fibrillation. Circulation. 2015;131(2): $157-164$.

57. Mak KH. Coronary and mortality risk of novel oral antithrombotic agents: a meta-analysis of large randomised trials. BMJ Open. 2012; 2(5)

58. Loke YK, Pradhan S, Yeong JK, Kwok CS. Comparative coronary risks of apixaban, rivaroxaban and dabigatran: a meta-analysis and adjusted indirect comparison. Br J Clin Pharmacol. 2014;78(4):707-717.

59. Singh M, Moningi S, Shah T, Arora R. Safety and efficacy of oral factor XA inhibitors in patients with acute coronary syndromes: a systemic metaanalysis of randomized controlled trials. J Am Coll Cardiol. 2012;59: E525-E525.

60. Komocsi A, Vorobcsuk A, Kehl D, Aradi D. Use of new-generation oral anticoagulant agents in patients receiving antiplatelet therapy after an acute coronary syndrome: systematic review and meta-analysis of randomized controlled trials. Arch Intern Med. 2012;172(20): $1537-1545$

61. Oldgren J, Wallentin L, Alexander JH, et al. New oral anticoagulants in addition to single or dual antiplatelet therapy after an acute coronary syndrome: a systematic review and meta-analysis. Eur Heart J. 2013;34(22): $1670-1680$.

62. Xu H, RuffCT, Giugliano RP, et al. Abstract 19119: Concomitant Use of Antiplatelet Therapy with Edoxaban or Warfarin in Patients with Atrial Fibrillation in the ENGAGE AF-TIMI 48 Trial. Circulation. 2014;130: A19119.

63. Hurlen M, Abdelnoor M, Smith P, Erikssen J, Arnesen H. Warfarin, aspirin, or both after myocardial infarction. NEngl J Med. 2002;347(13): 969-974.

64. Guthrie B, McCowan C, Davey P, Simpson CR, Dreischulte T, Barnett $\mathrm{K}$. High risk prescribing in primary care patients particularly vulnerable to adverse drug events: cross sectional population database analysis in Scottish general practice. BMJ. 2011;342:d3514.

65. Piccini JP, Hellkamp AS, Mahaffey KW, et al. Abstract 15686: Polypharmacy and the Efficacy and Safety of Rivaroxaban versus Warfarin in the Prevention of Stroke: Results From the ROCKET AF Trial. Circulation. 2014;130:A15686.

66. Skov J, Bladbjerg EM, Sidelmann J, Vamosi M, Jespersen J. Plenty of pills: polypharmacy prevails in patients of a Danish anticoagulant clinic. Eur J Clin Pharmacol. 2011;67(11):1169-1174. 
67. Hartter S, Sennewald R, Schepers C, Baumann S, Fritsch H, Friedman J. Pharmacokinetic and pharmacodynamic effects of comedication of clopidogrel and dabigatran etexilate in healthy male volunteers. Eur $J$ Clin Pharmacol. 2013;69(3):327-339.

68. Lamberts M, Lip GY, Hansen ML, et al. Relation of nonsteroidal antiinflammatory drugs to serious bleeding and thromboembolism risk in patients with atrial fibrillation receiving antithrombotic therapy: a nationwide cohort study. Ann Intern Med. 2014;161(10):690-698.

69. Gnoth MJ, Buetehorn U, Muenster U, Schwarz T, Sandmann S. In vitro and in vivo P-glycoprotein transport characteristics of rivaroxaban. J Pharmacol Exp Ther. 2011;338(1):372-380.

70. Wang L, Zhang D, Raghavan N, et al. In vitro assessment of metabolic drug-drug interaction potential of apixaban through cytochrome P450 phenotyping, inhibition, and induction studies. Drug Metab Dispos. 2010; 38(3):448-458.

71. Bathala MS, Masumoto H, Oguma T, He L, Lowrie C, Mendell J. Pharmacokinetics, biotransformation, and mass balance of edoxaban, a selective, direct factor Xa inhibitor, in humans. Drug Metab Dispos. 2012;40(12): 2250-2255.

72. Kubitza D, Becka M, Mueck W, Zuehlsdorf M. Safety, tolerability, pharmacodynamics, and pharmacokinetics of rivaroxaban - an oral, direct factor Xa inhibitor-are not affected by aspirin. JClin Pharmacol. 2006;46(9): 981-990.

73. Mueck W, Eriksson BI, Bauer KA, et al. Population pharmacokinetics and pharmacodynamics of rivaroxaban - an oral, direct factor Xa inhibitor - in patients undergoing major orthopaedic surgery. Clin Pharmacokinet. 2008;47(3):203-216.

74. Mueck W, Kubitza D, Becka M. Co-administration of rivaroxaban with drugs that share its elimination pathways: pharmacokinetic effects in healthy subjects. Br J Clin Pharmacol. 2013;76(3):455-466.

75. Mendell J, Noveck RJ, Shi M. Pharmacokinetics of the direct factor Xa inhibitor edoxaban and digoxin administered alone and in combination. J Cardiovasc Pharmacol. 2012;60(4):335-341.

76. Ogata K, Mendell-Harary J, Tachibana M, et al. Clinical safety, tolerability, pharmacokinetics, and pharmacodynamics of the novel factor Xa inhibitor edoxaban in healthy volunteers. J Clin Pharmacol. 2010;50(7): $743-753$.

77. Chin A Paw MJ, Dekker JM, Feskens EJ, Schouten EG, Kromhout D. How to select a frail elderly population? A comparison of three working definitions. J Clin Epidemiol. 1999;52(11):1015-1021.

78. Fried LP, Tangen CM, Walston J, et al. Frailty in older adults: evidence for a phenotype. J Gerontol A Biol Sci Med Sci. 2001;56(3):M146-M156.

79. Polidoro A, Stefanelli F, Ciacciarelli M, Pacelli A, Di Sanzo D, Alessandri C. Frailty in patients affected by atrial fibrillation. Arch Gerontol Geriatr. 2013;57(3):325-327.

80. Udompanich S, Lip GY, Apostolakis S, Lane DA. Atrial fibrillation as a risk factor for cognitive impairment: a semi-systematic review. QJM. 2013;106(9):795-802.

81. Fumagalli S, Tarantini F, Guarducci L, et al. Atrial fibrillation is a possible marker of frailty in hospitalized patients: results of the GIFA Study. Aging Clin Exp Res. 2010;22(2):129-133.
82. Avila-Funes JA, Carcaillon L, Helmer C, et al. Is frailty a prodromal stage of vascular dementia? Results from the Three-City Study. J Am Geriatr Soc. 2012;60(9):1708-1712.

83. Fang MC, Chen J, Rich MW. Atrial fibrillation in the elderly. Am J Med. 2007;120(6):481-487.

84. O'Brien EC, Simon DN, Allen LA, et al. Reasons for warfarin discontinuation in the Outcomes Registry for Better Informed Treatment of Atrial Fibrillation (ORBIT-AF). Am Heart J. 2014;168(4):487-494.

85. Perera V, Bajorek BV, Matthews S, Hilmer SN. The impact of frailty on the utilisation of antithrombotic therapy in older patients with atrial fibrillation. Age Ageing. 2009;38(2):156-162.

86. Flaker GC, Pogue J, Yusuf S, et al. Cognitive function and anticoagulation control in patients with atrial fibrillation. Circ Cardiovasc Qual Outcomes. 2010;3(3):277-283.

87. Jacobs V, Woller SC, Stevens S, et al. Time outside of therapeutic range in atrial fibrillation patients is associated with long-term risk of dementia. Heart Rhythm. 2014;11(12):2206-2213.

88. Donze J, Clair C, Hug B, et al. Risk of falls and major bleeds in patients on oral anticoagulation therapy. Am J Med. 2012;125(8):773-778.

89. Man-Son-Hing M, Laupacis A. Anticoagulant-related bleeding in older persons with atrial fibrillation: physicians' fears often unfounded. Arch Intern Med. 2003;163(13):1580-1586.

90. Man-Son-Hing M, Nichol G, Lau A, Laupacis A. Choosing antithrombotic therapy for elderly patients with atrial fibrillation who are at risk for falls. Arch Intern Med. 1999;159(7):677-685.

91. Katz S, Ford AB, Moskowitz RW, Jackson BA, Jaffe MW. Studies of Illness in the Aged. The Index of Adl: A Standardized Measure of Biological and Psychosocial Function. JAMA. 1963;185:914-919.

92. Chatterjee S, Sardar P, Biondi-Zoccai G, Kumbhani DJ. New oral anticoagulants and the risk of intracranial hemorrhage: traditional and Bayesian meta-analysis and mixed treatment comparison of randomized trials of new oral anticoagulants in atrial fibrillation. JAMA Neurol. 2013;70(12): 1486-1490.

93. Fried LP, Ferrucci L, Darer J, Williamson JD, Anderson G. Untangling the concepts of disability, frailty, and comorbidity: implications for improved targeting and care. J Gerontol A Biol Sci Med Sci. 2004;59(3): 255-263.

94. Stangier J. Clinical pharmacokinetics and pharmacodynamics of the oral direct thrombin inhibitor dabigatran etexilate. Clin Pharmacokinet. 2008; 47(5):285-295.

95. Kubitza D, Becka M, Zuehlsdorf M, Mueck W. Body weight has limited influence on the safety, tolerability, pharmacokinetics, or pharmacodynamics of rivaroxaban (BAY 59-7939) in healthy subjects. J Clin Pharmacol. 2007;47(2):218-226.

96. Pilotto A, Ferrucci L, Franceschi M, et al. Development and validation of a multidimensional prognostic index for one-year mortality from comprehensive geriatric assessment in hospitalized older patients. Rejuvenation Res. 2008;11(1):151-151.
Clinical Interventions in Aging

\section{Publish your work in this journal}

Clinical Interventions in Aging is an international, peer-reviewed journal focusing on evidence-based reports on the value or lack thereof of treatments intended to prevent or delay the onset of maladaptive correlates of aging in human beings. This journal is indexed on PubMed Central, MedLine,
Dovepress

CAS, Scopus and the Elsevier Bibliographic databases. The manuscript management system is completely online and includes a very quick and fair peer-review system, which is all easy to use. Visit http://www.dovepress. com/testimonials.php to read real quotes from published authors. 